Conclusion The association glucosamine sulfate - nimesulide is effective and safe; glucosamine sulfate is an effective symptomatic and structure modifying slow acting drug for the treatment of knee OA, that may be able to stabilise the joint space width and to modulate bone and joint metabolism.

\section{AB0151 DIPROSPAN EFFICACY IN PERIARTICULAR SYMPTOMS OF OSTEARTHRITIS}

RA Khabirov, LG Salikhov, SA Lapshina, KN Agisheva, RG Mukhina, LI Myasoutova. Department of Internal Medicine, Kazan State Medical University, Kazan, Russia

\subsection{6/annrheumdis-2001.413}

Background Complex clinical and instrumental investigations (kinesthesical method, electromyography (EMG), thermovision, ultrasonography) showed significant involvement (up to $80 \%$ ) of periarticular structures (muscles, tendons) in osteoarthritis (OA) aggravating the clinical picture of the disease and leading to the decrease of life quality of the patients. The substrate of myofascial pain syndrome are local densities in muscular tissue and in the places of detachment of tendons to the bones.

Objectives The goal of investigation was to study the diprospan efficacy in treatment of 30 patients with OA with muscular syndrome. The treatment efficacy was estimated by Lee and Reachy indices of muscular syndrome, the volume of active and passive movements of joints and by EMG.

Methods In case of revealing of painful trigger zones in the muscles surrounding the joints we injected locally $1 \mathrm{ml}$ of diprospan. In order to increase the volume of medication we added $5-10 \mathrm{ml}$ of $0.5 \%$ novocaine solution into the syringe.

Results During the first 24-36 h after the periarticular injection of diprospan there was found decrease of myalgias and arthralgias. Further on the volume of movements in joints increased and functional activity of patients improved as well. No local side effects after periarticular diprospan injections were noted in contrast to kenalog injections. The diprospan injections were repeated if necessary depending on clinical picture of OA.

Conclusion Periarcicular diprospan injections are effective and safe in patients with OA with myofascial pain syndrome.

\section{OP0008 STRUCTURE MODIFICATION IN OSTEOARTHRITIS WITH INTRA-ARTICULAR SODIUM HYALURONATE OF MOL. 500-730 KDA}

${ }^{1}$ RW Jubb, ${ }^{2} S$ Piva, ${ }^{2} \mathrm{~L}$ Beinat, ${ }^{3} \mathrm{~J}$ Dacre, ${ }^{4} \mathrm{P}$ Gishen, On behalf of the UK Hyalgan Study Group. 'Rheumatology Department, UHB Trust, Birmingham; ${ }^{2}$ Medical Department, Fidia SpA, Abano Terme, Italy; ${ }^{3}$ UCL London; ${ }^{4}$ Radiology Department, King's College Hospital, London, UK

\subsection{6/annrheumdis-2001.414}

Background Several Hyaluronan based products are available for intra-articular administration. These products differ in their composition and contain either natural hyaluronan of differing molecular weight or chemically crosslinked hyaluronan. Numerous clinical studies have shown that a series of 3-5 weekly intraarticular injections of hyaluronan of molecular weight 500-730 $\mathrm{kDa}$ (Hyalgan) reduces pain and improves function in patients with osteoarthritis of the knee and that this effect can be long lasting (6-12 months). Moreover, there is some evidence from pilot clinical studies to suggest that this product may slow osteoarthritis.
Objectives The primary objective of the present study was to examine the structure-modifying activity of intra-articular hyaluronan of molecular weight 500-730 kDa.(Hyalgan).

Methods A multicentre, randomised, placebo-controlled, doubleblind (masked observer) study in patients with primary knee osteoarthritis (ACR criteria) was conducted in 17 centres in the UK. The primary end point was the change in radiological joint space between baseline and one year in the medial tibio-femoral compartment, measured by digital image analysis. Weight-bearing antero-posterior radiographs were taken using a standardised technique. Patients were randomly assigned to receive 3 courses of 3 intra-articular injections of hyaluronan or $2 \mathrm{ml}$ of placebo (saline solution) during the one year study. Uncontrolled use of analgesics and NSAIDs were allowed.

Results 408 patients with knee osteoarthritis (II-III Kellgren-Lawrence) were enrolled in the trial and 319 patients completed the one year study period. Mean patient age was $64.2 \mathrm{yrs}$ (sd = 9.3), $68.4 \%$ of patients were female. The two groups, placebo and control, were comparable at entry for disease state and demographics. The change in joint space width between baseline and one year in the two groups was compared by analysis of variance. The group of patients with greater joint space at entry, treated with hyaluronan, showed statistically reduced progression of joint space narrowing. In the hyaluronan group the mean loss was only $-0.22(\mathrm{sd}=1.1)$, while in the placebo group the mean loss was -0.60 (sd $=1.1)$. This was statistically significant, $\mathrm{p}<$ 0.05 .

Conclusion Repeat treatment cycles of intra-articular hyaluronan of molecular weight $500-730 \mathrm{kDa}$ (Hyalgan) result in a statistically significant delay in radiological joint space narrowing within one year, in patients with osteoarthritis of the knee.

\section{OP0048 A DOUBLE-BLIND, PLACEBO-CONTROLLED DOSE RANGING STUDY TO EVALUATE THE EFFICACY OF VALDECOXIB, A NOVEL COX-2 SPECIFIC INHIBITOR, IN TREATING THE SIGNS AND SYMPTOMS OF OSTEOARTHRITIS OF THE KNEE}

${ }^{1} \mathrm{JJ}$ Fiechtner, ${ }^{2} \mathrm{D}$ Sikes, ${ }^{3} \mathrm{D}$ Recker. ${ }^{1}$ Rheumatology Clinic, East Lansing; ${ }^{2} \mathrm{Clinical}$ Research Division, Florida Medical Clinic, Zephyr Hills; ${ }^{3}$ Research and Development, Pharmacia Corporation, Skokie, USA

\subsection{6/annrheumdis-2001.415}

Background Valdecoxib is a novel oral COX-2 specific inhibitor being developed for the treatment of pain and inflammation, which does not cause the side effects commonly associated with the COX-1 inhibition of conventional NSAIDs.

Objectives The objective of this study was to evaluate the efficacy of multiple doses of valdecoxib in treating the signs and symptoms of osteoarthritis (OA) of the knee.

Methods In this multicenter, double-blind, placebo-controlled, parallel-group, dose-ranging study, $642 \mathrm{OA}$ patients were randomised to receive valdecoxib $0.5,1.25,2.5,5$ or $10 \mathrm{mg}$ BID, valdecoxib $10 \mathrm{mg}$ QD, naproxen $500 \mathrm{mg}$ BID, or placebo BID for 6 weeks. Patient's Assessment of Arthritis Pain (visual analogue scale, VAS), Patient's Global Assessment of Arthritis (VAS) and Western Ontario and McMasters Universities (WOMAC) OA Index were assessed at Baseline and after 1, 2, and 6 weeks of treatment. Vital signs and adverse events were monitored throughout the study.

Results Valdecoxib demonstrated efficacy that was significantly greater than placebo $(\mathrm{p}<=0.05$ ) in all primary efficacy measures listed above, at every dose except $0.5 \mathrm{mg}$ BID. 
Improvements in OA signs and symptoms in response to valdecoxib were dose-dependent, with the greatest improvements in primary efficacy measures observed at $5 \mathrm{mg}$ BID, $10 \mathrm{mg}$ QD, and $10 \mathrm{mg}$ BID, compared with placebo ( $\mathrm{p}<=0.004$ ). Valdecoxib doses of $5 \mathrm{mg}$ BID, $10 \mathrm{mg}$ QD, and $10 \mathrm{mg}$ BID were also as effective as naproxen $500 \mathrm{mg}$ in the treating signs and symptoms of OA. There were no statistically significant differences between any of the treatment groups in the number of adverse events or in vital signs or clinical laboratory measurements.

\begin{tabular}{|c|c|c|}
\hline \multicolumn{3}{|c|}{ Abstract OP0048 Table 1} \\
\hline & $\begin{array}{l}\text { Least Square Mean Change } \\
\text { from Baseline at Week } 2\end{array}$ & $\begin{array}{l}\text { Least Square Mean Change } \\
\text { from Baseline at Week } 6\end{array}$ \\
\hline Placebo & $-11.46^{*}$ & $-10.44^{*}$ \\
\hline $\begin{array}{l}\text { Valdecoxib } 0.5 \\
\mathrm{mg} \text { BID }\end{array}$ & $-13.84^{*}$ & $-15.74^{*}$ \\
\hline $\begin{array}{l}\text { Valdecoxib } 1.25 \\
\mathrm{mg} \text { BID }\end{array}$ & $-19.09^{\star *}$ & $-24.32^{* *}$ \\
\hline $\begin{array}{l}\text { Valdecoxib } 2.5 \\
\mathrm{mg} \text { BID }\end{array}$ & $-24.30^{\star *}$ & $-28.08^{\star *}$ \\
\hline $\begin{array}{l}\text { Valdecoxib } 5 \mathrm{mg} \\
\text { BID }\end{array}$ & $-28.12^{* *}$ & $-29.42^{* *}$ \\
\hline $\begin{array}{l}\text { Valdecoxib } 10 \\
\mathrm{mg} \text { QD }\end{array}$ & $-27.77^{* *}$ & $-29.50^{* *}$ \\
\hline $\begin{array}{l}\text { Valdecoxib } 10 \\
\text { mg BID }\end{array}$ & $-30.28^{* *}$ & $-29.24^{* *}$ \\
\hline $\begin{array}{l}\text { Naproxen } 500 \\
\text { mg BID }\end{array}$ & $-27.76^{* *}$ & $-30.05^{* *}$ \\
\hline
\end{tabular}

Conclusion Valdecoxib is an effective therapy among patients with symptomatic $\mathrm{OA}$ of the knee. Valdecoxib doses of $5 \mathrm{mg}$ BID, $10 \mathrm{mg}$ QD, and $10 \mathrm{mg}$ BID are maximally efficacious, as they are superior to placebo and comparable to naproxen 500 mg BID in all primary efficacy measures. Valdecoxib is well tolerated at all doses.

Sponsored by Pharmacia Corporation and Pfizer, Inc.

\section{OP0049 A POOLED INDEX TO ASSESS SEVERITY OF OSTEOARTHRITIS OF THE HIP OR KNEE. PERFORMANCE IN A RANDOMISED, DOUBLE BLIND, MULTICENTER, CROSSOVER CLINICAL TRIAL OF DICLOFENACI MISOPROSTOL (ARTHROTEC) COMPARED TO ACETAMINOPHEN IN PATIENTS WITH OSTEOARTHRITIS OF THE HIP OR KNEE}

T Pincus, T Sokka. Division of Rheumatology, Vanderbilt University, Nashville, USA

\subsection{6/annrheumdis-2001.416}

Background A pooled index of various measures, such as the disease activity index (DAS) in rheumatoid arthritis, can provide advantages over individual measures to assess disease severity, analyse responses to therapy, and improve statistical power in a clinical trial or observational study.

Objectives To apply an index of four measures of severity of osteoarthritis of the hip or knee, the Western Ontario McMaster (WOMAC) scale, visual analogue scale (VAS) for pain, KellgrenLawrence radiographic stage, and number of joints involved among two hips and two knees, in analyses of results of a randomised, controlled clinical trial of diclofenac/misoprostol (Arthrotec, ARTH) compared to acetaminophen (ACET).

Methods 227 patients with radiographic stage 2-4 osteoarthritis of the hip or knee received either 6 weeks of ARTH $75 \mathrm{mg}$ twice a day or ACET $1,000 \mathrm{mg}$ four times a day after a washout period, and then the other drug for 6 weeks, in a randomised, double-blind, multicenter, crossover clinical trial. A pooled index to recognise patients who had mild osteoarthritis was developed according to 4 criteria: location in only one knee, Kellgren-Lawrence stage 2 , lowest tertile at screening for the WOMAC, and lowest tertile at screening for the pain VAS. The value of the pooled index was 0 (mildest) if 3 or 4 of the indicators applied to a patient; the value was 1 if 2 indicators applied to a patient, 2 if only one indicator applied to a patient, and 3 (most severe) if no indicator applied to a patient.

Results Overall, WOMAC pain scores were improved by 7.8 of 100 units $(\mathrm{p}<0.001)$, and pain VAS scores were improved by 14.6 of 100 units $(\mathrm{p}<0.001$ ), while taking ARTH versus ACET. Differences between changes in WOMAC scores while taking ARTH versus ACET were -0.8 (advantage to ACET) for 26 patients with a pooled index of $0(\mathrm{p}=0.86)$, compared to 1.5 (advantage to ARTH) for 50 patients with a pooled index of $1(\mathrm{p}=0.70), 6.8$ for 74 patients with a pooled index of $2(\mathrm{p}=$ $0.06)$, and 14.7 for 77 patients with pooled index of 3 ( $\mathrm{p}<$ 0.001). Differences between changes in pain VAS scores while taking ARTH versus ACET were 0.9 (advantage to ARTH) for patients with a pooled index of $0(\mathrm{p}=0.88)$, compared to 8.8 for patients with a pooled index of $1(\mathrm{p}=0.11), 14.0$ for patients with a pooled index of $2(\mathrm{p}=0.002)$, and 22.1 for patients with a pooled index of $3(\mathrm{p}<0.001)$.

Conclusion A pooled index of four measures of severity of osteoarthritis of the hip or knee, the WOMAC, pain VAS, Kellgran-Lawrence radiographic stage, and number of joints involved can be applied to analyse results of a clinical trial, and may be useful to stratify patients in clinical trials and clinical care.

\section{REFERENCE}

1 Goldsmith $\mathrm{CH}$, Smythe $\mathrm{HA}$, Helewa A. Interpretation and power of pooled index. J Rheumatol. 1993;20:575-8

\section{OP0050 IMMUNOGENETIC ASPECTS OF EROSIVE OSTEOARTHRITIS OF THE HAND}

R Ramonda, L Punzi, A Businaro, E Musacchio, F Schiavon, M Podswiadek, G Cardinale, $\mathrm{S}$ Todesco. Divisions of Rheumatology and Clinical Medicine, Department of Medical and Surgical Sciences, University of Padova, Padova, Italy

\subsection{6/annrheumdis-2001.417}

Background Erosive osteoarthritis of hand (EOA) is believed to be a subset of generalised OA characterised by frequent inflammatory episodes and an aggressive clinical course.

Objectives Since rare studies are available on the risk factors of EOA, we investigated its immunogenetic predisposition.

Methods In 47 patients with EOA (42 F, mean age $62.8 \pm 8$ years), HLA typing for A, B, C, DRB1 loci was performed. In the same patients we also evaluated the number of active joints (NAJ), the number of X-ray erosions (NEJ), the radiographic score (RS, Kallman), along with ESR and CRP.

Results The HLA antigens most frequently found in the 47 patients with EOA were A2 $(16=34 \%)$, B5 $(13=27.7 \%)$, Cw4 $(13=27.7 \%)$, and DRB1011 $(11=23.4 \%)$ and DRB103 $(8=17 \%)$. Interestingly, the frequency of these two latter antigens were higher in EOA than in non-EOA patients (DRB1011 